\title{
Effects of Fruit Maturity Stages on GC-FID Fatty Acid Profiles, Phenolic Contents, and Biological Activities of Eucalyptus marginata L.
}

\author{
Hanene Ghazghazi $\mathbb{D}^{1},{ }^{1}$ Badiaa Essghaier $\mathbb{D}^{2},{ }^{2}$ Ichrak Jawadi, ${ }^{1}$ Leila Riahi $\mathbb{D}{ }^{3}$ \\ Ridha Ben Salem $\mathbb{D}^{4}{ }^{4}$ and Ghayth Rigane $\mathbb{D}^{4,5}$ \\ ${ }^{1}$ Laboratory of Management and Valorization of Forest Resources LR161INRGREF01, B. P 10,2080 Ariana, \\ National Institute for Research in Rural Engineering Water and Forest (INRGREF), University of Carthage, Tunis, Tunisia \\ ${ }^{2}$ Laboratory of Mycology,Pathology and Biomarkers, Department of Biology, Sciences Faculty of Tunis, \\ University of Tunis El Manar, Tunis, Tunisia \\ ${ }^{3}$ Laboratory of Biotechnology and Bio-Geo Resources Valorization BVBGR-LR11ES31, University of Manouba, \\ Higher Institute of Biotechnology of Sidi Thabet,2020, Ariana, Tunisia \\ ${ }^{4}$ Laboratory of Organic Chemistry LR17ES08, Faculty of Sciences of Sfax, B. P 1171,3038, University of Sfax, Sfax, Tunisia \\ ${ }^{5}$ Chemistry-Physics Department, Faculty of Sciences and Technology of Sidi Bouzid, University of Kairouan, B. P 380, \\ 9100 Sidi Bouzid, Tunisia \\ Correspondence should be addressed to Ghayth Rigane; gaith.rigane@yahoo.fr
}

Received 10 February 2021; Revised 10 May 2021; Accepted 30 June 2021; Published 16 July 2021

Academic Editor: Alejandro Hernández

Copyright (c) 2021 Hanene Ghazghazi et al. This is an open access article distributed under the Creative Commons Attribution License, which permits unrestricted use, distribution, and reproduction in any medium, provided the original work is properly cited.

\begin{abstract}
The objective of this study was to determine the impact of development stages of Eucalyptus marginata's fruits on the fatty acid composition as well as on phenolic, flavonoid, and tannin contents of oils. Taking into account fruit maturity stages, vegetable oils have been evaluated for their biological potentials. Fatty acid profiles were quantified using gas chromatography (GC) coupled to a flame ionization detector (FID). The fatty acid profiles of oils obtained from mature fruits showed highest linoleic acid content (49.21\%) and Z-vaccenic (C18:1n-7) + oleic (C18:1n-9) acids (22.40\%) and a low content of linolenic acid (C18:3) (1.59\%). On the other hand, the major saturated fatty acid compound found in the oil of immature Eucalyptus marginata fruits was palmitic acid (C16:0) with about $27 \%$. Based on the Folin-Ciocalteau method, the obtained results revealed a significant difference in the contents of total polyphenols, flavonoids, and tannins according to the stage of fruit maturity $(p<0.05)$. Furthermore, the detected antimicrobial potentials were related to the fruit maturity stage. While both vegletable oils extracted from mature and immature Eucalyptus marginata fruits exhibited notable antibacterial activities against the species Staphylococcus aureus, Enterococcus faecalis, Serratia marcescens, and Escherichia coli, only the oils extracted from immature fruits exhibited an antifungal activity against Candida parapsilosis.
\end{abstract}

\section{Introduction}

In general, Eucalyptus species (Myrtaceae) are fast growing trees exploited for paper pulp but also as essential oil sources and ornamental plants [1]. Eucalyptus is a native Australian tree, represented by more than 900 species. It has been introduced worldwide, including Tunisia [2]. Looking back on the traditional use of Eucalyptus species, traditional remedies for the treatment of various diseases such as pulmonary tuberculosis, influenza, fungal infections, head colds, rheumatoid disease, muscular pain, bronchitis, inflammations, respiratory infections, cold, flu and sinus congestion, and diabetes have been formulated from its active ingredients [2]. Recent studies have reported that the polyphenols found in Eucalyptus leaves including acylphenols and their derivatives, flavonoids, tannins, and 
triterpenoids and their glycosides have a wide range of biological activities, including antiaging, anti-inflammatory, and antitumor potentialities [3]. As part of an extensive phytochemical analysis of Eucalyptus marginata L. oils, in literature, no reports have described the fatty acid profiling and biological activities in correlation to the maturity stage. In view of these data, the objectives of this research were to study the impact of maturity stages on (1) the oil yield, (2) total phenol, flavonoid, and tannin contents, (3) fatty acid composition, and (3) some biological potentialities including antioxidant and antimicrobial activities.

\section{Materials and Methods}

2.1. Plant Material and Sample Preparation. Fruits from Eucalyptus marginata were collected at immaturity and full maturity stages, in 2018, from Souiniet Arboreta in the northeastern region of Tunisia $\left(35^{\circ} 54 \mathrm{~N}\right.$ and $\left.8^{\circ} 48 \mathrm{E}, 492 \mathrm{~m}\right)$ characterized by semiarid bioclimate. A voucher specimen of Eucalyptus marginata (LR11INRGREF01), at immaturity and full maturity stages, respectively, was deposited at the Laboratory of Management and Valorization of Forest Resources, Tunisia. The harvesting of Eucalyptus marginata fruits was achieved with pruning shears on various mature trees selected at random at different heights and the four cardinal points. Transport of samples was performed in ventilated plastic boxes. The fruits' color and relative moisture contents were adopted as a ripening criterion (Table 1). Indeed, only full green fruits were harvested at the initial stages of maturity, while only brown fruits were selected for analysis during the final stages of maturity. Moisture contents were determined by heating in an airoven at $60^{\circ} \mathrm{C}$ to constant weight.

After that, fruits were finely grounded using an electric grinder to get a fine powder that was kept in closed containers (vials) until analyses.

2.2. Oil Extraction. Briefly, $100 \mathrm{~g}$ dry weights of each Eucalyptus marginata fruit powder were extracted using a Soxhlet apparatus with $n$-hexane for 3 hours at $69^{\circ} \mathrm{C}$. Finally, the obtained fruit oils were stored in black glass bottles and kept in a cold room at $+4^{\circ} \mathrm{C}$ until further use.

2.3. Fatty Acid Composition Analysis. The fatty acid composition of the oils was determined using an EEC 2568/1991 [4] method to prepare fatty acid methyl esters (FAMEs), followed by a chromatographic analysis step which was performed in a Hewlett Packard 6890 gas chromatography using a capillary column (Stabilwax, Restek, length $50 \mathrm{~m}$, internal diameter $0.32 \mathrm{~mm}$, and film thickness $0.25 \mu \mathrm{m}$ ). The column temperature was isothermal at $180^{\circ} \mathrm{C}$, the injector temperature was $230^{\circ} \mathrm{C}$, and the detector temperature was $250^{\circ} \mathrm{C}$. Fatty acids were identified by comparing retention times with standard compounds including lauric (C12:0), tridecylic (C13:0), myristic (C14:0), palmitic (C16:0), hypogeic (C16:1n-9) + palmitoleic (C16:1n-7), stearic (C18 : $0)$, oleic $(\mathrm{C} 18: 1 \mathrm{n}-9)+Z$-vaccenic $(\mathrm{C} 18: 1 \mathrm{n}-7)$, linoleic (C18 : 2), linolenic (C18:3), arachidic (C20:0), gadoleic (C20:1), behenic (C22:0), and erucic (C22:1) acids expressed as percentages of fatty acid methyl esters. Results were expressed as relative percent of total area.

2.4. Extraction of Phenolic Fraction from Eucalyptus marginata Fruit Oil. The phenolic extracts were obtained following the procedure in [5] with some modifications. In brief, the oil sample $(4 \mathrm{~g})$ was added to $2 \mathrm{~mL}$ of $n$-hexane and $4 \mathrm{~mL}$ of methanol/water $(80: 20, v / v)$ solution in a $20 \mathrm{~mL}$ centrifuge tube. After vigorous mixing, they were centrifuged for $3 \mathrm{~min}(6000 \mathrm{rpm})$. The hydroalcoholic phase was collected and the hexanic phase was re-extracted twice with $4 \mathrm{~mL}$ of methanol/water $(80: 20, v / v)$ solution each time. Finally, the hydroalcoholic fractions were combined and then washed with $4 \mathrm{~mL}$ of $n$-hexane to remove the residual oil. After the evaporation of the hydroalcoholic extract to dryness, the residue was stored in a glass container at $0^{\circ} \mathrm{C}$ in the dark until its use.

2.5. Total Polyphenolic, Flavonoid, and Tannin Contents. Total polyphenolic contents were estimated based on the Folin-Ciocalteau method as described in $[6,7]$ with slight modifications using a UV-visible spectrometer (BECKMAN DU 800). Total polyphenolic contents were calculated based on a gallic acid calibration curve $\left(r^{2}=0.914\right)$ and expressed as $\mathrm{mg}$ gallic acid equivalent (GAE)/g dry weight (DW). The total flavonoid content was estimated as reported previously [8]. The total flavonoid content was quantified using the rutin standard curve $\left(r^{2}=0.996\right)$ and expressed as mg rutin equivalent (RE)/g DW. On the other hand, the condensed tannin content (CT) was determined by the method used in [5]. The content of the $\mathrm{CT}$ in the $\mathrm{MeOH}-\mathrm{H}_{2} \mathrm{O}$ extracts was expressed as mg catechin equivalent $(\mathrm{CE}) / \mathrm{g} \mathrm{DW}$.

\subsection{Antioxidant Activity}

2.6.1. DPPH Radical Scavenging Activity. The free radicalscavenging capacity was measured using the DPPH method as previously described $[7,8]$. Aliquots $(1.5 \mathrm{~mL})$ of various dilutions of the plant extracts were mixed with $1.5 \mathrm{~mL}$ of methanolic DPPH solution $(0.2 \mathrm{mM})$. The mixtures were incubated for $30 \mathrm{~min}$ at $25^{\circ} \mathrm{C}$, and then the absorbance at $520 \mathrm{~nm}$ was measured using a UV-visible spectrometer (BECKMAN DU 800). The absorbance in the presence of the plant extract was recorded as $A_{\text {sample, while the absorbance }}$ of the control reaction was recorded as $A_{\text {blank. Radical }}$ scavenging activity, expressed as percent inhibition, was calculated by using the following formula:

$$
\text { radical scavenging activity }(\%)=\left[\frac{A_{\text {blank }}-A_{\text {sample }}}{A_{\text {blank }}}\right] \times 100 \text {. }
$$

Radical scavenging activity was expressed as $\mathrm{IC}_{50}(\mathrm{mg} /$ $\mathrm{mL}$ ), defined as the concentration of the extract required to cause a $50 \%$ decrease in the initial DPPH concentration. Ascorbic acid was used as the positive control. All measurements were performed in triplicate. 
TABLE 1: Harvest date, fruit color and state of maturity, and relative moisture and oil contents of Eucalyptus marginata during maturation.

\begin{tabular}{lccc}
\hline Harvest date & Fruit color, state of maturity & Relative moisture content $(\%, w / w)$ & Oil content $(\%, w / w)$ \\
\hline March 2018 & Green & $85.7 \pm 0.09^{\mathrm{a}}$ & $3.90 \pm 0.02^{\mathrm{a}}$ \\
May 2018 & Brown & $11.5 \pm 0.01^{\mathrm{b}}$ & $6.60 \pm 0.01^{\mathrm{b}}$ \\
\hline
\end{tabular}

Values in the same row with different superscript letters are significantly different at $p<0.05$.

2.6.2. ABTS Radical Cation Scavenging Activity. The ABTS radical scavenging activity of the Eucalyptus marginata fruit extracts was performed using the method in [9]. The antioxidant capacities of the Eucalyptus marginata fruit extracts were evaluated using a standard curve obtained by measuring the absorbance of Trolox solutions $(0.2-0.8 \mathrm{mM})$.

\subsection{Antimicrobial Activity}

2.7.1. Microorganisms and Culture Conditions. The dilution of the investigated Eucalyptus marginata fruit extracts was achieved in DMSO. Lists of Tunisian pathogenic clinical strains used to test the antimicrobial activity of both oil extracts were as follows: the four Gram-negative bacteria (Escherichia coli, Enterobacter cloacae, Klebsiella pneumoniae, and Serratia marcescens), two Gram-positive bacteria (Staphylococcus aureus and Enterococcus faecalis), and two yeast strains (Candida parapsilosis and Candida sake).

2.7.2. Agar Diffusion Method. The agar well diffusion method was used to evaluate the antimicrobial activity of our oil extracts as previously described [10]. For microdilution assay, the Müller-Hinton medium (BioRad, France) was used for bacterial strains and yeast malt extract agar YMA (BioRad, France) for antifungal tests. The freshly prepared cell suspension $(0.1 \mathrm{~mL})$ adjusted to $10^{7} \mathrm{CFU} / \mathrm{mL}$ for bacteria and $10^{5}$ spores $/ \mathrm{mL}$ for yeast species was inoculated onto the surface of agar plates. Afterwards, wells with $6 \mathrm{~mm}$ diameter were punched into the inoculated agar medium and $20 \mu \mathrm{L}$ of the tested extract oil was added. Negative controls consisted of $20 \mu \mathrm{L}$ of DMSO. Three positive controls were also used, namely, ceftazidime CAZ30 as an antibiotic and voriconazole $V C Z$ and amphotericin $B$ as fungicides. The plate was allowed to stand for $30 \mathrm{~min}$ at $4^{\circ} \mathrm{C}$ to permit the diffusion of the oil extracts, followed by incubation at $37^{\circ} \mathrm{C}$ for $24 \mathrm{~h}$. The antimicrobial activity was evaluated by measuring the zones of inhibition (clear zone around the well) against the pathogenic microorganisms. All tests were repeated three times.

2.8. Determination of Minimum Inhibitory Concentration (MIC) and Minimal Bactericidal Concentration (MBC). The minimum inhibitory concentration (MIC) of both the tested oils was determined using the microdilution broth method. The MIC was estimated visually by the absence of turbidity [10]. The minimal bactericidal concentration (MBC) was determined from the microdilution plates used in the MIC assay, according to the method described in [11]. An aliquot of $10 \mu \mathrm{L}$ of each well without visible growth was transferred to plates containing the broth media culture and incubated at $37^{\circ} \mathrm{C}$ for $24 \mathrm{~h}$, and then the colony growth was verified. All assays were performed in triplicate.

2.9. Statistical Analysis. Results were expressed as mean\pm standard deviation (SD) of 3 measurements for analytical determination. Statistical differences were calculated using a one-way analysis of variance (ANOVA), followed by Student's $t$-test. Differences were considered significant at $p<0.05$.

\section{Results and Discussion}

3.1. Phenolic Secondary Metabolite Contents. The variation in the phenolic secondary metabolites of the oils prepared from Eucalyptus marginata fruits according to different stages of maturity was evaluated. The obtained results showed a significant difference in the total polyphenolic content according to the stage of maturity $(p<0.05)$. Indeed, the oil of mature Eucalyptus marginata fruits was most rich in total polyphenols ( $25 \pm 0.02 \mathrm{mg} \mathrm{GAE} / \mathrm{g} \mathrm{DW}$ ) compared to that of immature fruits $(12 \pm 0.02 \mathrm{mg} \mathrm{GAE} / \mathrm{g} \mathrm{DW})$ (Table 2).

Globally, these results were not in agreement with previous studies published by Santos et al. [12] who claimed that the total phenolic content using $\mathrm{EtOH}: \mathrm{H}_{2} \mathrm{O}$ (50:50, $v / v)$ as the solvent was $159.57 \pm 6.75 \mathrm{mg} \mathrm{GAE} \mathrm{g}^{-1}$ of extract; this value is in the range of previously published data for Eucalyptus globulus grown in Portugal [13]. On the other hand, the mentioned data are appreciably lower than that obtained with $\mathrm{MeOH}: \mathrm{H}_{2} \mathrm{O}(50: 50, v / v)$ (407.41 mg GAE $\mathrm{g}^{-1}$ of extract). Moreover, Santos et al. (2012) reported that when they used supercritical solvents, the total phenolic content decreases significantly to values between 9.22 and $33.10 \mathrm{mg} \mathrm{GAE} \mathrm{g}^{-1}$ of extract for $\mathrm{CO}_{2} / \mathrm{H}_{2} \mathrm{O}$ and $\mathrm{CO}_{2} / \mathrm{EtOH}$, respectively.

In literature, rare data mentioned the polyphenolic contents of the vegetable oil of Eucalyptus marginata, which led us to compare the obtained results with other works carried out on oils extracted from other species like olive oil. The last oil was well known for its high content of phenols as previously reported by Rigane et al. [14] who described that the phenolic content varied from 150 to $700 \mathrm{mg} \mathrm{GAE} / \mathrm{kg}$ for some Tunisian olive oils. On the other hand, olive oil was characterized by a significant decrease in the phenolic content during different maturity stages. For example, Ben [15] claimed that values for the olive oils extracted from green stage olives were significantly higher than those obtained from other olive oil samples and decreased with the ripening of the fruits. 
TABLE 2: Oil content, total phenolic, flavonoid, and tannin contents, and antioxidant activities in Eucalyptus marginata L. immature and mature fruit extracts.

\begin{tabular}{lcc}
\hline & Immature fruit stage & Full maturation fruit stage \\
\hline Total phenolic content (mg GAE/g DW) & $12.00 \pm 0.02^{\mathrm{a}}$ & $25.00 \pm 0.02^{\mathrm{b}}$ \\
Total flavonoid content (mg RE/g DW) & $3.90 \pm 0.03^{\mathrm{a}}$ & $13.90 \pm 0.07^{\mathrm{b}}$ \\
Condensed tannin content (mg CE/g DW) & $1.50 \pm 0.05^{\mathrm{a}}$ & $5.00 \pm 0.08^{\mathrm{b}}$ \\
DPPH assay (mg/mL) & $7.00 \pm 0.09^{\mathrm{a}}$ & $3.01 \pm 0.04^{\mathrm{b}}$ \\
ABTS assay (mg/mL) & $13.02 \pm 0.01^{\mathrm{a}}$ & $10.05 \pm 0.00^{\mathrm{b}}$ \\
\hline
\end{tabular}

Results are expressed as mean \pm standard deviation of 3 determinations. Different letters in the same line indicate significant differences $(p<0.05)$.

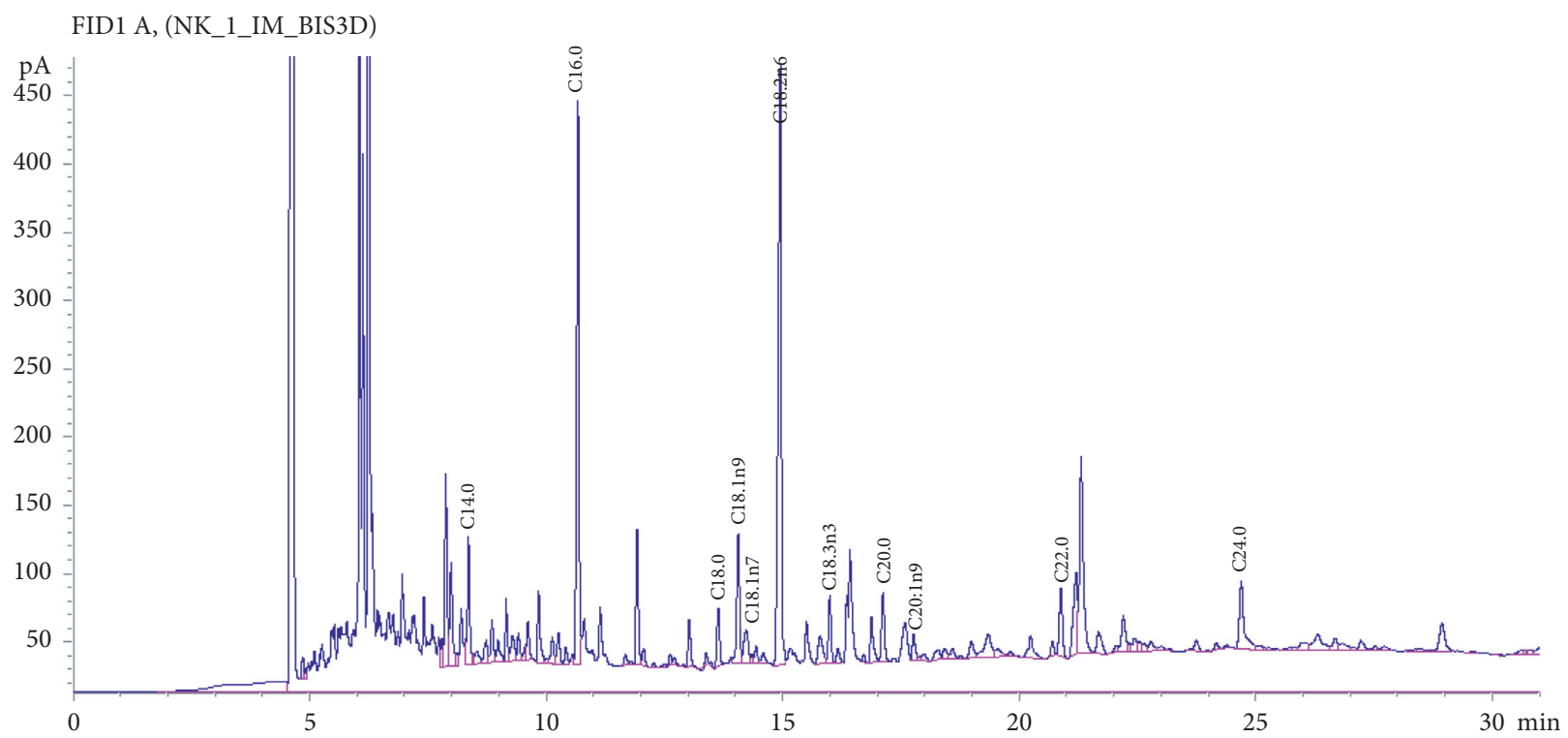

FIGURE 1: GC-FID chromatogram of fatty acid composition of the oil extracted from immature Eucalyptus marginata L fruits.

The same tendency was observed in the content of flavonoids and condensed tannins (Table 2). The results gave the highest flavonoid and condensed tannin contents at full maturity stage of fruits $(13.9 \pm 0.070 \mathrm{RE} / \mathrm{g} \mathrm{DW}$ and $5 \pm 0.08 \mathrm{mg} \mathrm{CE} / \mathrm{g} \mathrm{DW}$, respectively).

Previous studies have shown that several factors can influence the contents of flavonoids like geographic, climatic, and genetic ones. The degree of maturity of the plant and the duration of storage also have a strong influence on the content of these compounds [16].

3.2. Eucalyptus marginata Oil Yield. Analyses related to Eucalyptus marginata oil yield indicated a significant difference during maturity stages $(p<0.05)$. It was noted that the oil extracted from the mature Eucalyptus marginata fruits has a higher yield (6.6\%) than that from the immature $E u$ calyptus marginata fruits (3.9\%) (Table 2). These results were slightly higher than those reported by Domingues et al. [18] in Eucalyptus maidenii (6.1\%), Eucalyptus grandis (3.1\%), and Eucalyptus urograndis (1.7\%). These differences may be due to several factors such as the genetic background, harvest period, and the development stage of the plant [18-21].

3.3. Lipid Profiles. The chromatographic profiles related to the determination of the vegetable oil's fatty acid composition in Eucalyptus marginata species during maturation stages of fruits are represented in Figures 1 and 2. Table 3 shows the fatty acid composition ( $\% \mathrm{~m} / \mathrm{m}$ methyl esters) of the oils obtained from immature and mature fruits. The fatty acid composition of the oil from the two maturity stages was characterized by its high content of linoleic acid (38.51-49.21\%), followed by palmitic acid (26.55-14.48\%) and $Z$-vaccenic (C18:1n-7)+oleic (C18:1n-9) acids (8.85-21.9\%) (Table 3 ). The analysis of Table 3 reveals considerable quantitative differences in fatty acid contents among the stages of maturity: the quantity of $Z$-vaccenic (C18:1n-7) + oleic (C18:1n-9) acids strongly increases from 8.85 to $22.44 \%$, while the amount of palmitic acid (C16:0) decreases from 26.55 to $14.48 \%$. On the other hand, a slight decrease was observed for myristic (C14:0), linoleic (C18:3), arachidic (C20:0), behenic (C22:0), erucic (C22:1), and lignoceric (C24:0) acids. In addition, UFA predominated over SFAs, and particularly PUFAs predominasted over MUFAs in oils extracted from Eucalyptus marginata fruits at full maturation. SFAs were the predominant fatty acid classes in oils extracted from immature Eucalyptus marginata L. fruits, and this result could be explained by the high content of palmitic (26.55\%), myristic (4.55\%), arachidic (4.26\%), and behenic (4.34\%) acids in immature Eucalyptus marginata L. fruits. Furthermore, the fatty acid composition during the fruit maturity stage could be explained as follows: there is potential for pathway crossover in organisms where the delta-9 desaturase acts on a palmitoyl CoA (coenzyme A) 
FID1 A, (NK_2_IM_BIS3D)

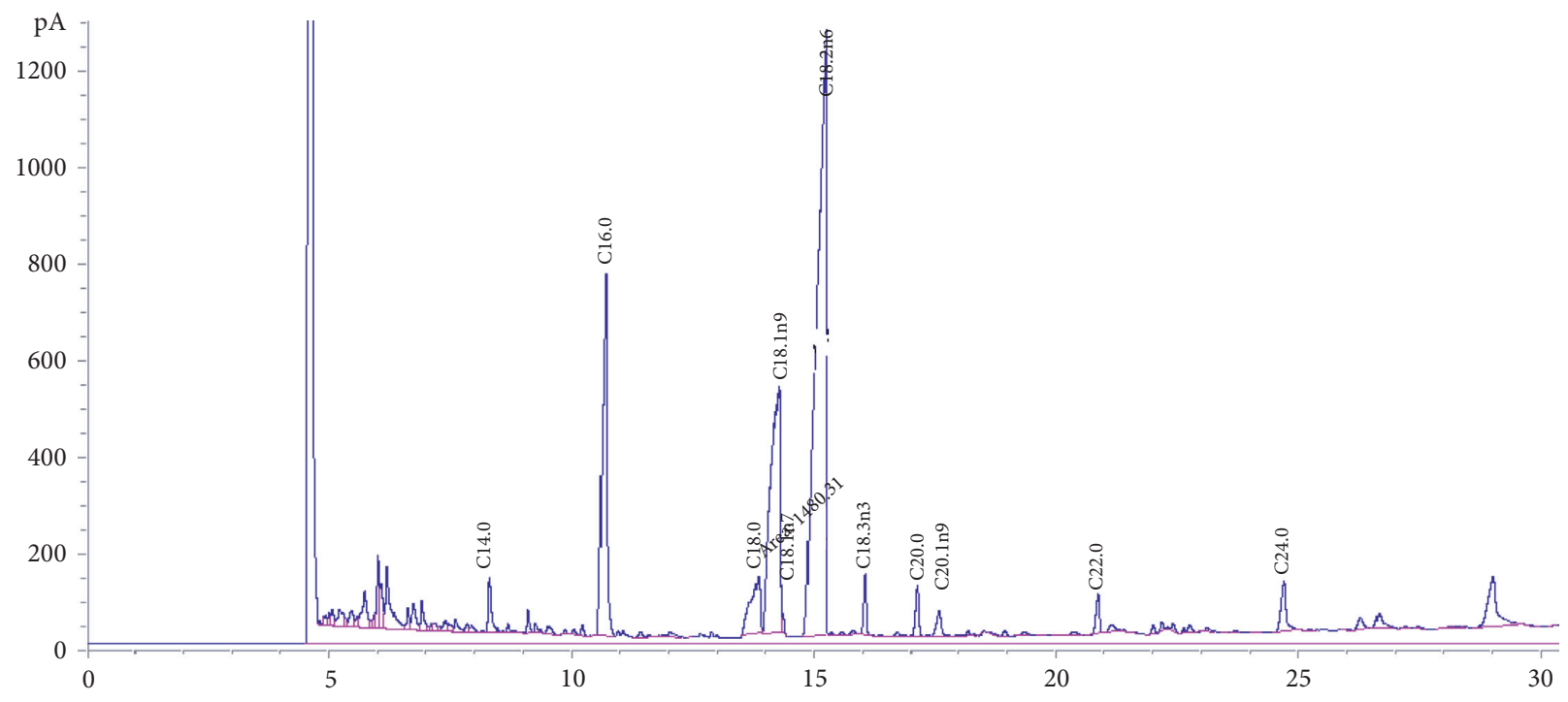

FIGURE 2: GC-FID chromatogram of fatty acid composition of the oil extracted from mature Eucalyptus marginata L fruits.

TABLE 3: Fatty acid composition in vegetable oils of immature and mature Eucalyptus marginata L. fruits.

\begin{tabular}{lcc}
\hline & Immature fruit stage (\%) & Full maturation fruit stage (\%) \\
\hline Myristic acid (C14:0) & $4.55 \pm 0.00^{\mathrm{a}}$ & $1.52 \pm 0.00^{\mathrm{b}}$ \\
Palmitic acid (C16:0) & $26.55 \pm 0.05^{\mathrm{a}}$ & $14.48 \pm 0.01^{\mathrm{b}}$ \\
Stearic acid (C18:0) & $3.35 \pm 0.08^{\mathrm{a}}$ & $4.84 \pm 0.00^{\mathrm{b}}$ \\
Z-Vaccenic (C18:1n-7) + oleic (C18:1n-9) acids & $8.85 \pm 0.01^{\mathrm{a}}$ & $22.40 \pm 0.02^{\mathrm{b}}$ \\
Linoleic acid (C18:2) & $38.51 \pm 0.07^{\mathrm{a}}$ & $49.21 \pm 0.09^{\mathrm{b}}$ \\
Linolenic acid (C18:3) & $3.37 \pm 0.04^{\mathrm{a}}$ & $1.59 \pm 0.00^{\mathrm{b}}$ \\
Arachidic acid (C20:0) & $4.26 \pm 0.01^{\mathrm{a}}$ & $1.45 \pm 0.02^{\mathrm{b}}$ \\
Behenic acid (C22:0) & $4.34 \pm 0.02^{\mathrm{a}}$ & $1.24 \pm 0.05^{\mathrm{b}}$ \\
Erucic acid (C22:1) & $1.37 \pm 0.02^{\mathrm{a}}$ & $1.09 \pm 0.06^{\mathrm{b}}$ \\
Lignoceric acid (C24:0) & $4.85 \pm 0.02^{\mathrm{a}}$ & $2.19 \pm 0.02^{\mathrm{b}}$ \\
C18:1/C18:2 & $0.22 \pm 0.04^{\mathrm{a}}$ & $0.45 \pm 0.09^{\mathrm{b}}$ \\
$\sum$ SFAs & $47.90 \pm 0.18^{\mathrm{a}}$ & $25.72 \pm 0.10^{\mathrm{b}}$ \\
$\sum$ MUFAs & $10.22 \pm 0.03^{\mathrm{a}}$ & $23.49 \pm 0.08^{\mathrm{b}}$ \\
$\sum$ PUFAs & $41.88 \pm 0.11^{\mathrm{a}}$ & $50.80 \pm 0.09^{\mathrm{b}}$ \\
M UFAs & $52.10 \pm 0.14^{\mathrm{a}}$ & $74.29 \pm 0.17^{\mathrm{b}}$ \\
\hline MUFAs/ $\sum$ PUFAs & $0.80 \pm 0.54^{\mathrm{a}}$ & $0.68 \pm 0.08^{\mathrm{b}}$ \\
\hline
\end{tabular}

SFAs, saturated fatty acids; PUFAs, polyunsaturated fatty acids; MUFAs, monounsaturated fatty acids; UFAs, unsaturated fatty acids. Results are expressed as mean \pm standard deviation of 3 determinations. Different letters in the same line indicate significant differences $(p<0.05)$.

to give palmitoleoyl CoA $(9 Z-C 16: 1)$ that is subsequently elongated to cis-vaccenate. Until recently, it was thought that the purely anaerobic and aerobic routes were mutually exclusive in any given organism. However, the authors in [22] have shown using specific gene knockout studies that Pseudomonas aeruginosa employs both pathways to generate the monounsaturated fatty acids required to regulate membrane lipid fluidity.

The present study proved that Eucalyptus marginata L. fruit oil was a source of beneficial fatty acids such as oleic and linoleic acids. Taking into account that linoleic acid is one of the essential fatty acids, named as omega- 6 fatty acids, consequently, they are an essential dietary requirement for all mammals, allowing the biosynthesis of arachidonic acid and thus some prostaglandins. Linoleic acid has become increasingly popular in the cosmetic industry because of its beneficial properties on the skin, including anti-inflammatory, acne reduction, and moisture retention properties [22]. By comparing our results to those found in the literature, in this work, the obtained results were different from those cited in [23], which mentioned that the major fatty acids found in Eucalyptus gunnii leaves were $\alpha$-linolenic acid (C18:3), followed by linoleic acid (C18:2) and palmitic acid (C16:0).

3.4. Antioxidant Activities of Eucalyptus marginata Oils. To compare the antioxidant potential of the investigated fruit oils, DPPH and ABTS radical scavenging activities were tested and the results are presented in Table 2 . The results revealed that DPPH and ABTS radical scavenging activities ranged from $7 \mathrm{mg} / \mathrm{mL}$ to $3.01 \mathrm{mg} / \mathrm{mL}$ and $13.02 \mathrm{mg} / \mathrm{mL}$ to 


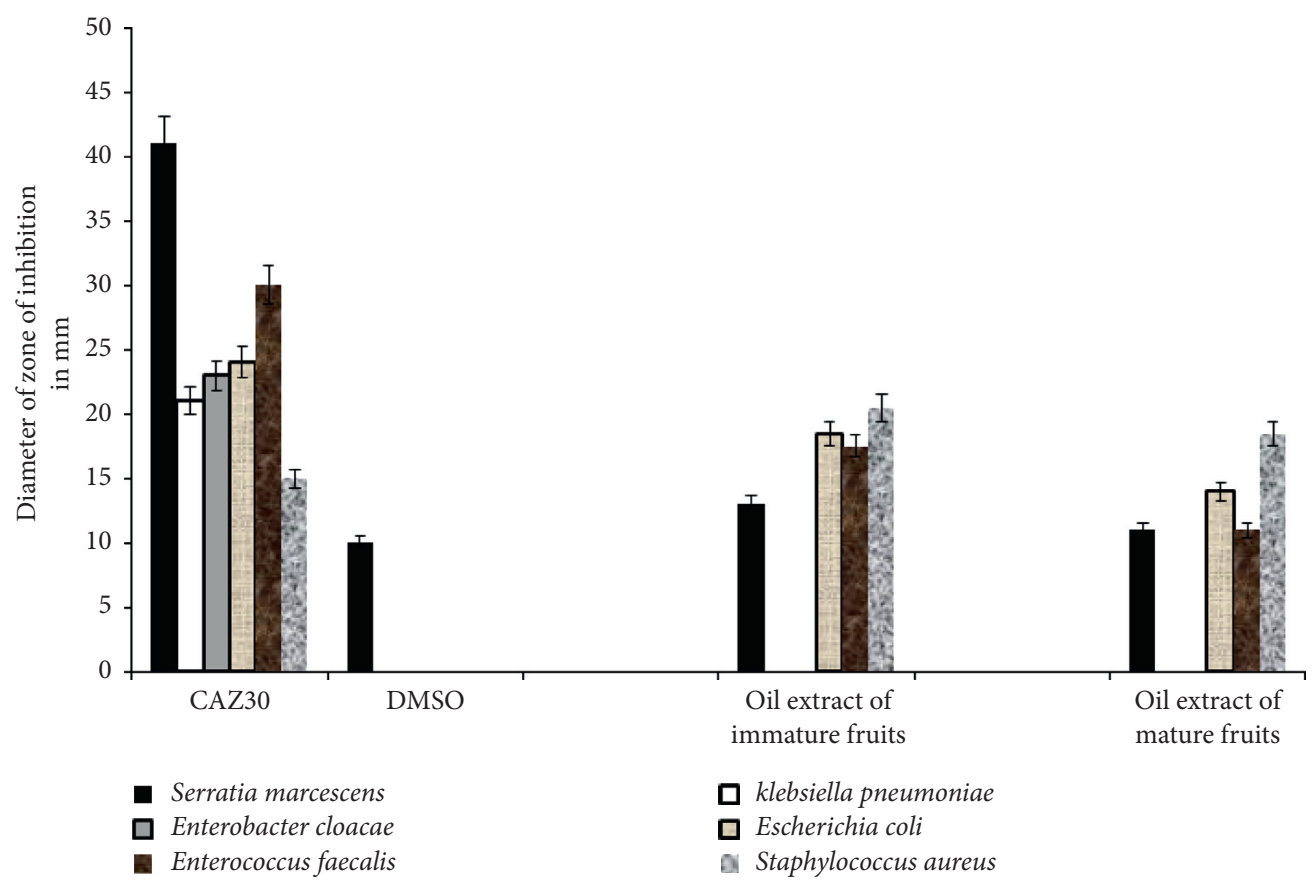

Figure 3: Antibacterial activities of oils extracted from both mature and immature fruits of Eucalyptus marginata against six Tunisian clinical bacterial species compared to the commercialized antibiotic ceftazidime CAZ30.

$10.05 \mathrm{mg} / \mathrm{mL}$, respectively, at immature and full mature stages. It is evident that the oil extracted from Eucalyptus marginata fruit at full maturity exhibit highest antiradical activity $(p<0.05)$ as compared to oils extracted at immature stages. It is also noted that the sample of the oil extracted from immature fruits could inhibit DPPH and ABTS radicals despite having recorded an average content of total polyphenols. According to the literature, the antioxidant activity is positively correlated with the structure of polyphenols; the presence of a high number of hydroxyl groups in polyphenols has the highest antioxidant activity due to their power to give more atoms to stabilize free radicals [23-25].

\subsection{Antimicrobial Activity Evaluation}

3.5.1. Antibacterial Activity. The antibacterial activity of Eucalyptus marginata oil extracts was assessed by the well diffusion method based on six bacterial strains. Among the six tested bacterial species, both the oils extracted from the mature and immature fruits are effective against four species of pathogenic bacteria. The oil extract obtained from immature fruits was more bioactive against the four tested bacteria with diameters of inhibition zones ranging from $17 \mathrm{~mm}$ to $21 \mathrm{~mm}$, while the obtained diameters for mature fruits vary from $11 \mathrm{~mm}$ to $19 \mathrm{~mm}$ (Figure 3).

The highest inhibition diameters were seen with the vegetable oil of immature Eucalyptus marginata fruits with $21 \mathrm{~mm}$ against Staphylococcus aureus, $19 \mathrm{~mm}$ against Escherichia coli, and $18 \mathrm{~mm}$ against Enterococcus faecalis. Our results were in agreement with those found by Mota et al. [26], who demonstrated that the essential oil from Eucalyptus tereticornis Sm exhibited antibacterial activity.
3.5.2. Antifungal Activity. With regard to the antifungal activity, the effect of the oils against Candida parapsilosis and Candida sake is illustrated in Figure 4. These results show that no extract was able to inhibit Candida sake species. On the other hand, only $36 \mathrm{mg} / \mathrm{mL}$ of oil obtained from fruits at full maturation was active against Candida parapsilosis. and the value of the inhibition diameter was $13 \mathrm{~mm}$. On the other hand, it should be noted that the extract of mature fruits was more efficient against Candida parapsilosis than the commercialized fungicide amphotericin B used in this study, which reported a small diameter of inhibition of about $10 \mathrm{~mm}$. Both Candida species are more sensitive to the VCZ30 fungicide with an inhibition diameter of $35.5 \mathrm{~mm}$. The obtained results confirm those of Mota et al. [26], who reported that the essential oil of Eucalyptus tereticornis Sm has also fungicide activity able to completely destroy Saccharomyces spp., Sporobolomyces, and Hansenula.

3.6. Determination of MIC and MBC of Oils Extracted from Mature and Immature Fruits. The determination of the MIC and $\mathrm{MBC}$ of antimicrobial agents presents important criteria of its pharmaceutical performance; the lower the values of both MIC and MBC, the more the antimicrobial agents are effective against the indicated microorganisms. The well diffusion method was applied to determine the MIC and $\mathrm{MBC}$ values of the mature and immature fruit extracts of Eucalyptus marginata. The obtained results given in Table 4 show the efficiency of the oil at immature stage as antibacterial agent with its lowest value MIC equal to 0.37 (mg/ $\mathrm{mL})$ compared to $1.25(\mathrm{mg} / \mathrm{mL})$ against Escherichia coli exhibited by the mature fruit oil extract. Both the oil extracts showed the same efficiency against Serratia marcescens with MIC and MBC, respectively, of 0.15 and $0.075 \mathrm{mg} / \mathrm{mL}$. 


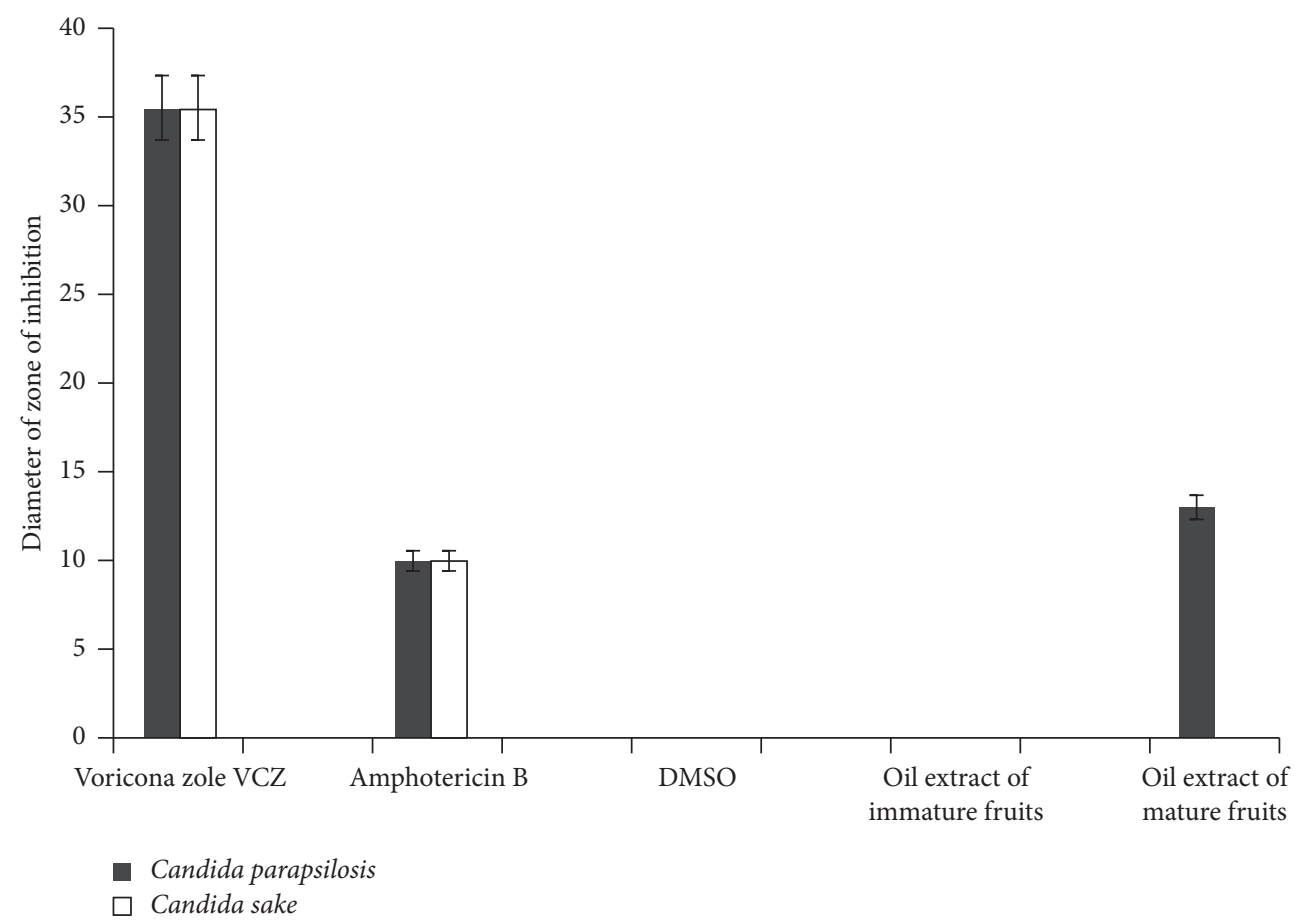

FIgURE 4: Antifungal activities of oils extracted from both mature and immature fruits of Eucalyptus marginata against Candida parapsilosis and Candida sake compared to the commercialized fungicides amphotericin B and voriconazole VCZ.

TABLE 4: MIC and MBC of oil extracts of Eucalyptus marginata fruits at immature and mature stages against the clinically tested microbial strains.

\begin{tabular}{lcccc}
\hline $\begin{array}{l}\text { Clinical } \\
\text { pathogens }\end{array}$ & \multicolumn{2}{c}{ Oil of immature fruits } & \multicolumn{2}{c}{ Oil of mature fruits } \\
MIC & MBC & MIC & MBC \\
\hline $\begin{array}{l}\text { Serratia } \\
\text { marcescens }\end{array}$ & $0.15 \pm 0.00$ & $0.075 \pm 0.00$ & $0.15 \pm 0.02$ & $0.075 \pm 0.00$ \\
$\begin{array}{l}\text { Escherichia coli } \\
\text { Staphylococcus } \\
\text { aureus }\end{array}$ & $0.37 \pm 0.47$ & $0.18 \pm 0.00$ & $1.25 \pm 0.10$ & $0.62 \pm 0.68$ \\
$\begin{array}{l}\text { Enterococcus } \\
\text { faecalis }\end{array}$ & $1.25 \pm 0.14$ & $0.62 \pm 0.00$ & $1.25 \pm 0.47$ & $0.62 \pm 0.00$ \\
$\begin{array}{l}\text { Candida } \\
\text { parapsilosis }\end{array}$ & ND & ND & $9.00 \pm 0.00$ & $6.00 \pm 0.00$ \\
\hline
\end{tabular}

Values are expressed in $\mathrm{mg} / \mathrm{mL}$. Results are expressed as mean \pm standard deviation of 3 determinations. ND: not detected.

Identical sensibility of the two bacterial species Staphylococcus aureus and Enterococcus faecalis with the same MIC and $\mathrm{MBC}$ of $0.56 \mathrm{mg} / \mathrm{mL}$ was observed toward both mature and immature oil extracts.

In the present study, the MBC values of both the oil extracts of Eucalyptus marginata were determined. Only the oil extract of mature fruits was active against Candida parapsilosis with low MIC and MBC values of, respectively, $9 \mathrm{mg} / \mathrm{mL}$ and $6 \mathrm{mg} / \mathrm{mL}$. The effect of oil extracts is related to the bacterial cell wall type; in Gram-negative bacteria, the outer membrane constitutes an effective permeability barrier; lipopolysaccharide, thanks to its negative surface charges, prevents the diffusion of hydrophobic molecules [27]. However, Gram-positive bacteria are less protected because the wall is formed of a layer of peptidoglycan only, causing an increase in ion permeability and the leakage of vital intracellular constituents, i.e., a deficiency in the enzymatic system of the bacteria [28]. Our study showed a significant activity of the oils extracted from Eucalyptus marginata against Gram-negative bacteria than Grampositive bacteria. This result is very interesting from the perspective of an application of these vegetable oils as an antibacterial agent, but it is necessary to broaden the spectrum of the bacterial strains tested in order to confirm their performance.

The oils extracted from mature and immature fruits were more active against Gram-positive bacteria than Gramnegative bacteria which corroborate results obtained for the essential oils of Perovskia abrotanoides reported by Mahboubi and Kazempour [29], unlike the essential oil of Eucalyptus which exhibits comparable activity against Gramnegative and Gram-positive bacteria [30].

The detected difference was explained by the chemical composition and the origin of the oil. The high antibacterial activity of the oil extracted from immature fruits could be explained by its specific fatty acid composition, based on the higher amounts of palmitic, linolenic, arachidic, behenic acid, and lignoceric acid as well as SFAs compared to the oil extracted from mature fruits. These mentioned results were recently confirmed by the work of Emre et al. [31] who showed that the presence of palmitic and linolenic acids resulted in considerable biological effects.

The oil extracted from mature fruits was efficient against the fungi species Candida parapsilosis, which may be explained by its richness in phenolic and flavonoid contents as well as its highest antioxidant activities (ABTS and $\mathrm{DPPH})$, compared to that from the immature ones. A 
positive correlation between antioxidant and antimicrobial potentialities in oil extracts was previously reported [32]. The antibacterial potential could be explained by the richness of extracts in oleic, stearic, and linoleic acids. These findings were confirmed by those reported by Emre et al. [31].

A significant correlation between the fatty acid composition and the biological activities was reported in [32, 33]. These authors concluded that the aqueous extract of Labisia pumila Benth consisted mainly of fatty acids and palmitic, stearic, oleic, and linoleic acids exhibited antioxidant and antibacterial activities. Thus, the antioxidant and antimicrobial activities of oils extracted from immature and mature fruits described in this investigation could be attributed to their fatty acid composition and phenolic secondary metabolites varying during the maturation.

\section{Conclusion}

Phenolic contents, fatty acid compositions, and antioxidant, antibacterial, and antifungal activities of oils extracted from immature and full mature Eucalyptus marginata fruits have been examined. The results revealed that the main fatty acid and phenolic contents were affected by maturity stage. On the other hand, the antioxidant activity of Eucalyptus marginata oil has also been studied based on DPPH and ABTS assays. Based on the results of these tests, the oil extracted from mature fruits showed higher significant antioxidant activity compared to that of immature fruits. The antimicrobial activities of the investigated oils were also evaluated, and the obtained findings revealed interesting activities against pathogenic bacteria as well as on the tested yeast species. These results valorize Eucalyptus marginata fruit oils as potential source of natural bioactive phytochemicals with wide applications in cosmetic, food, and pharmaceutical industries.

\section{Data Availability}

No data were used to support this study.

\section{Conflicts of Interest}

The authors hereby declare that there are no conflicts of interest.

\section{Acknowledgments}

The authors thank the Ministry of Higher Education and Scientific Research for financial support.

\section{References}

[1] Y. Cao, S. Fu, X. Zou, H. Cao, Y. Shao, and L. Zhou, “Antimicrobial activity of some essential oils and major constituents of essential oils," European Journal of Soil Biology, vol. 46, pp. 128-135, 2010.

[2] H. Ghazghazi, B. Essghaier, H Riguene et al., "Phytochemical analysis, antioxidant and antimicrobialactivities of eucalyptus essential oil: a comparative study between Eucalyptus marginata L. and Eucalyptus paucilora L," Revue Roumaine de Chimie, vol. 64, pp. 1055-1062, 2019.

[3] W. Li, X. Zhang, Z He et al., "In vitro and in vivo antioxidant activity of eucalyptus leaf polyphenols extract and its effect on chicken meat quality and cecum microbiota," Food Research International, vol. 136, Article ID 109302, 2020.

[4] European Union Commission, Regulation (EEC) 2568/1991, Official Journal of the European Communities (OJEC), Brussels, Belgium, 1991.

[5] A. Yahyaoui, M. O. Arfaoui, G Rigane et al., "Investigation on the chemical composition and antioxidant capacity of extracts from Crataegus azarolus L.: effect of growing location of an important Tunisian medicinal plant," Chemistry Africa, vol. 2, pp. 361-365, 2019.

[6] L. Garcia-Mier, A. E. Meneses-Reyes, S. N Jimenez-Garcia et al., "Polyphenol content and antioxidant activity of stevia and peppermint as a result of organic and conventional fertilization," Journal of Food Quality, vol. 2021, Article ID 6620446, 2021.

[7] O. Khedher, G. Rigane, R. Ben Salem, and Y. Moussaoui, "Optimization of polyphenols recovery from Schinus molle L. peel using response surface methodology (RSM)," Chemistry Africa, vol. 3, pp. 813-820, 2020.

[8] M. Ben Hmed, G. Rigane, G. Rigane, R. Ben Salem, and N. Zouari, "Phytochemical and antioxydant activities of Schinus molle L. extract," Revue Roumaine de Chimie, vol. 65, pp. 173-178, 2020.

[9] G. Rigane, R. Ben Salem, S. Sayadi, and M. Bouaziz, "Phenolic composition, isolation, and structure of a new deoxyloganic acid derivative from Dhokar and Gemri-Dhokar olive cultivars," Journal of Food Science, vol. 76, pp. 965-973, 2011.

[10] B. Essghaier, A. Naouar, J. Abdelhak, F. ZidM, and Z. N. Sadfi, "Synthesis, crystal structure and potential antimicrobial activities of di(4-sulfamoyl-phenyl-ammonium) sulphate," Microbiology Research, vol. 169, pp. 504-510, 2014.

[11] I. Khémiri, H. B. Essghaier, N. S. Zouaoui, N. Ben Gdara, and L. Bitri, "The antimicrobial and wound healing potential of Opuntia ficus indica L. inermis extracted oil from Tunisia," Evidence-Based Complementary and Alternative Medicine, vol. 2019, Article ID 6620446, , 2019.

[12] S. A. O. Santos, J. J. Villaverde, C. M. Silva, C. P. Neto, and A. J. D. Silvestre, "Supercritical fluid extraction of phenolic compounds from Eucalyptus globules Labill bark," The Journal of Supercritical Fluids, vol. 71, pp. 279-285, 2012.

[13] G. Vázquez, E. Fontenla, J. Santos, M. S. Freire, J. GonzálezÁlvarez, and G. Antorrena, "Antioxidant activity and phenolic content of chestnut (Castanea sativa) shell and eucalyptus (Eucalyptus globulus) bark extracts," Industrial Crops and Products, vol. 28, pp. 279-285, 2008.

[14] G. Rigane, M. Boukhris, M. Bouaaziz, S. Sayadi, and R. Ben Salem, "Analytical evaluation of two monovarietal virgin olive oils cultivated in the south of Tunisia: jemri-Bouchouka and Chemlali-Tataouin cultivars," Journal of the Science of Food and Agriculture, vol. 93, pp. 1242-1248, 2013.

[15] S. Ben Brahim and M. Bouaziz, "Characterization of rare virgin olive oils cultivated in southern Tunisia during fruits development process: major compounds and oxidative state in tandem with chemometrics," European Food Research and Technology, vol. 245, no. 4, pp. 939-949, 2019.

[16] A. A. Aganga and K. W. Mosase, "Tannin content, nutritive value and dry matter digestibility of Lonchocarpus capassa, Zizyphus mucronata, Sclerocarya birrea, Kirkia acuminata 
and Rhus lancea seeds," Animal Feed Science and Technology, vol. 91, no. 1-2, pp. 107-113, 2001.

[17] R. M. A. Domingues, G. D. A. Sousa, C. M. Silva, C. S. R. Freire, A. J. D. Silvestre, and C. Pascoal Neto, "High value triterpenic compounds from the outer barks of several Eucalyptus species cultivated in Brazil and in Portugal," Industrial Crops and Products, vol. 33, pp. 158-164, 2011.

[18] M. Elleuch, S. Besbes, O. Roiseux, C. Blecker, and H. Attia, "Quality characteristics of sesame seeds and by-products," Food Chemistry, vol. 103, pp. 641-650, 2007.

[19] N. Kadri, B. Khettal, Y. Aid, S. Kherfellah, W. Sobhi, and Barragan-MonteroV, "Some physicochemical characteristics of pinus (Pinus halepensis Mill., Pinus pinea L., Pinus pinaster and Pinus canariensis) seeds from North Algeria, their lipid profiles and volatile contents," Food Chemistry, vol. 188, pp. 184-192, 2015.

[20] G. Miliauskas, P. R. Venskutonis, and K. T. A. Van Bee, "Screening of radical scavenging activity of some medicinal and aromatic plant extracts," Food Chemistry, vol. 85, pp. 231-237, 2004.

[21] G. Rigane, J. Jebali, H. Ghazghazi, H. Riguene, M. L. Khouja, and R. Ben Salem, "Chemical composition and biological activities of Pinus halepensis Mill. oil," Revue Roumaine de Chimie, vol. 64, pp. 999-1006, 2019.

[22] K. Zhu, K. H. Choi, H. P. Schweizer, C. O. Rock, and Y. M. Zhang, "Two aerobic pathways for the formation of unsaturated fatty acids in Pseudomonas aeruginosa," Molecular Microbiology, vol. 60, pp. 260-273, 2006.

[23] R. Guimarães, L. Barros, A. M. Carvalho, M. J. Sousa, J. Sá Morais, and I. C. F. R. Ferreira, "Aromatic plants as a source of important phytochemicals: vitamins, sugars and fatty acids in Cistus ladanifer, Cupressus lusitanica and Eucalyptus gunnii leaves," Industrial Crops and Products, vol. 30, pp. 427-430, 2009.

[24] M. Chouaibi, L. Rezig, S. Hamdi, and G. Ferrari, "Chemical characteristics and compositions of red pepper seed oils extracted by different methods," Industrial Crops and Products, vol. 128, pp. 363-370, 2019.

[25] M. Chouaibi, L. Rezig, N Mahfoudhi et al., "Physicochemical characteristics and antioxidant activities of Zizyphus lotus L. seed oil," Journal of Food Biochemistry, vol. 37, pp. 454-463, 2013.

[26] V. S. Mota, R. N. T. Turrini, and V. B. Poveda, "Antimicrobial activity of Eucalyptus globulus oil, xylitol and papain: a pilot study," Rev Esc Enferm USP, vol. 49, pp. 216-220, 2015.

[27] H. Nikaido, "Multidrug resistance in bacteria," Annual Review of Biochemistry, vol. 78, pp. 119-146, 2009.

[28] D. Hogan and L. Kolter, "Why are bacteria refractory to antimicrobials?" Current Opinion in Microbiology, vol. 5, pp. 472-477, 2003.

[29] M. Mahboubi and N. Kazempour, "The antimicrobial activity of essential oil from Perovskia abrotanoides karel and its main components," Indian Journal of Pharmaceutical Sciences, vol. 71, pp. 343-347, 2009.

[30] T. Bosnić, D. Softić, and J. Grujić-Vasić, "Antimicrobial activity of some essential oils and major constituents of essential oils," Acta Medica Academica, vol. 35, pp. 19-22, 2006.

[31] T. Emre, B. Bulent, and A. Vecihi, "Investigation of the effects of some Herbal extracts used in different ratios on Meat Fatty acid profile level in experimental heat stress created in Broilers," in Poultry-an Advanced Learning, A. Ali Kamboh, Ed., IntechOpen, London, UK, 2019.

[32] K. Ehsan, Z. E. J. Hawa, G. H. Ali, and E. Mahdi, "Fatty acid composition, antioxidant and antibacterial properties of the microwave aqueous extract of three varieties of Labisia pumila Benth," Biological Research, vol. 48, p. 9, 2015.

[33] L. J. McGaw, A. K. Jäger, and J. van Staden, "Antibacterial effects of fatty acids and related compounds from plants," South African Journal of Botany, vol. 68, pp. 417-423, 2002. 